\title{
Thermal Degradation of Different Biomass to Fuel: Optimization of Process Parameters by Response Surface Methodology
}

\author{
Narayan Gouda 1(D), Achyut K. Panda 2,* (D) \\ 1 School of Applied Sciences, Centurion University of Technology and Management, Odisha, India; \\ gouda24narayan@gmail.com (N.G); \\ 2 Department of Chemistry, Veer Surendra Sai University of Technology Burla, Odisha, India, PIN: 768018; \\ achyut.panda@gmail.com (A.K.P); \\ * Correspondence: achyut.panda@gmail.com;
}

Scopus Author ID 30267909900

Received: 12.07.2020; Revised: 24.08.2020; Accepted: 26.08.2020; Published: 30.08.2020

\begin{abstract}
In the present study, the yield of different pyrolysis products was optimized using Response Surface Methodology (RSM). Here, User Defined Model and quadratic programming (QP) have been used to model and optimize the influence of two process parameters like reaction temperature and type of biomasses on the five responses such as oil yield, liquid yield, char yield, gas yield and reaction time using the experimental data obtained from the fast pyrolysis in a semi-batch reactor system. Mathematical model equations are derived for all the responses by using sets of experimental data and analysis of variance (ANOVA). ANOVA analysis showed that the model was very significant for all the responses. From the residual vs. predicted plots, the value of the coefficient of correlation $\left(\mathrm{R}^{2}\right)$ is found to be a good agreement with the experimental ones. From the optimization study, the liquid, oil, char, and gas yield at the optimum temperature $\left(584^{\circ} \mathrm{C}\right)$ of seed biomass are found to be $81.34 \%$, $70.12 \%, 9.8 \%$, and $9.64 \%$ respectively.
\end{abstract}

Keywords: Pyrolysis; biomass; optimization; Response Surface Methodology; User-Defined Model; Quadratic programming.

(C) 2020 by the authors. This article is an open-access article distributed under the terms and conditions of the Creative Commons Attribution (CC BY) license (https://creativecommons.org/licenses/by/4.0/).

\section{Introduction}

The consumption of energy in the world is increasing owing to the considerable growth of the population as well as industrialization. Most of the world's energy demand is fulfilled by fossil fuels such as coal, natural gases, and petroleum products, which will be exhausted in the near future. In addition, the use of fossil fuel creates some negative effects on the environment due to the emission of harmful gases like $\mathrm{CO}, \mathrm{CO}_{2}, \mathrm{NO}_{\mathrm{x}}, \mathrm{SO}_{\mathrm{x}}$, etc. In view of environmental pollution and the energy crisis, it is essential to make the utilization of clean and renewable resources such as biomass as a substitute for fossil fuel. There are various methods, including biochemical, mechanical, and thermochemical processes used to convert biomass into biofuel. The thermochemical conversion methods comprise combustion, gasification, liquefaction, and pyrolysis, etc. [1]. Among all thermochemical conversion processes, pyrolysis, especially fast pyrolysis, has received more interest as a promising technology for converting biomass to biofuel during current decades [2]. However, the process is still to be developed and needs to overcome many technical as well as economic barriers in order to compete with traditional techniques for fuel production. The final objective of this technology 
is to yield bio-oil with high heating values and better fuel characteristics for competing with and ultimately replacing the exhaustible fossil fuels. The development of cutting-edge technologies is the next challenge for pyrolysis researchers to succeed in this target.

The yield of different fuel from biomass through pyrolysis depends on different process parameters and the sorts of pyrolysis reactors being used. The identification of an optimized process for the production of different types of fuel from different biomass is required for designing an industrial process. Very few researchers focused on improving the process optimization through modeling, needed to adjust the parameters to maximize the production of different products. One of the best methods used to resolve the optimization problem is to apply a response surface methodology (RSM). The use of RSM, a statistical approach by many researchers are summarised below.

Wang et al. has optimized parameters like reaction temperature, pressure, and the mass of the loading pyrolytic carbon from waste LCD panels by using RSM in order to get a high Indium conversion rate from indium oxide. They stated the optimal temperature is $935^{\circ} \mathrm{C}$, the pressure is $5 \mathrm{~Pa}$, and the mass of loading pyrolytic carbon is 38\%[3]. Srivasta et al. used RSM for optimizing the parameters such as the temperature of the reaction, $\mathrm{Ni}$ - loading, and the ratio of catalyst to the biomass of the catalytic pyrolysis process of algae Tetraselmis sueicca. The optimal reaction temperature was found to be $464^{\circ} \mathrm{C}$, the ratio of catalyst to algae was 0.8 , and nickel loading was $2.7 \%$ to get the maximum hydrocarbon yield[4].Sakthivel et al. applied RSM to optimize the input parameters such as the concentration of bio-oil, compression ratio and a load of the engine in order to observe the influence of input parameters such as the concentration of on the engine performances such as brake specific fuel consumption, thermal brake efficiency, and emission analysis viz. hydrocarbon emission, $\mathrm{NO}_{\mathrm{x}}$ and $\mathrm{CO}_{\mathrm{x}}$ emissions. They reported the optimal input parameters as a compression ratio of 18:1, blend of fuel is $20 \%$, and the engine load is $100 \%$. The optimum values of BSFE and BTE were found to be $0.3088 \mathrm{~kg} / \mathrm{kWhr}$ and $31.96 \%$, respectively. The optimum values of the emission of smoke, $\mathrm{CO}$, $\mathrm{CO}_{2}, \mathrm{NO}_{\mathrm{x}}$, and $\mathrm{HC}$ were found to be $29.47 \%, 1.064 \%, 9.23 \%, 987 \mathrm{ppm}$, and $63 \mathrm{ppm}$, respectively[5].Saadat et al. employed RSM in order to know the effect of the parameters of the pyrolysis process, such as pyrolysis temperature and time on the responses such as adsorption of phosphates by the sewage sludge biochar enriched with $\mathrm{Ca}$ and $\mathrm{Mg}$. The optimal temperature and activation time for the pyrolysis process to get the activated biochar (with $100 \%$ efficiency for phosphorous removal) enriched with the ca be $694^{\circ} \mathrm{C}$ and $2.9 \mathrm{~h}$, respectively. In the case of $\mathrm{Mg}$-rich activated char, the optimum pyrolytic temperature and activation time was $700{ }^{\circ} \mathrm{C}$, and $1.8 \mathrm{~h}$, respectively, and the maximum efficiency of phosphorous removal was $57.3 \%[6]$. Roy et al. produced the biochar from the tea waste by pyrolysis process and used RSM to optimize the independent variables such as reaction temperature, contact time, and adsorbent dose in order to remove fluoride existing in the effluents. They reported the optimization technique showed a very good agreement between the experimental results and the responses predicted in the RSM model. The percentage of removal of fluoride at the optimum conditions was determined as $98.29 \%$ [7]. Pereira et al. applied the RSM to see the effects and optimize the factors such as $\mathrm{pH}$ and temperature in order to enhance the adsorption capacity of the pyrolyzed as well as functionalized sludge in removing the reactive red dye 120 from the aqueous solution. The optimal $\mathrm{pH}$ and temperature range for Pyrolysed and functionalized sludge were found to be $3.5,60{ }^{\circ} \mathrm{C}$ and $5.4,60{ }^{\circ} \mathrm{C}$, respectively. The corresponding efficiency of dye removal was reported $94 \%$ and $98 \%$, respectively[8].Li et al. has performed the optimization of the process parameters by RSM to 
prepare levulinic acid using magnetized iron oxide $(\mathrm{MIO}) / \mathrm{SO}_{4}{ }^{2-}$ corn straw pyrolyzed solid acid catalyst. The optimum hydrolysis temperature was found to be $249.66^{\circ} \mathrm{C}$, hydrolysis time was found to be of $67.3 \mathrm{~min}$, and the yield of LA was predicted to be $23.05 \%$ [9]. Kim et al. used RSM, a statistical approach to find the optimum condition for thermal desorption in order to recover the maximum number of preservatives from wood treated with copper naphthenate (CuNap). The optimum reaction temperature and time for the desorption process were estimated to be at $265^{\circ} \mathrm{Cand} 51 \mathrm{~min}$, respectively[10]. Intani et al. used a response surface methodology to find the optimum operating conditions for the production of biochar from the residue of maize. The optimal temperature, reaction time, heating rate for the pyrolysis of husk and leaf to get biochar were found to be $600{ }^{\circ} \mathrm{C}, 90 \mathrm{~min}, 5{ }^{\circ} \mathrm{C} / \mathrm{min}$, and $600{ }^{\circ} \mathrm{C}, 79 \mathrm{~min}, 15$ ${ }^{\circ} \mathrm{C} /$ min respectively [11]. Gupta et al. used RSM to optimize the process parameters such as temperature, the height of the sawdust packed bed, and nitrogen flow rate with an aim to increase the bio-oil and decrease the bio-char yield from the pyrolysis of sagwan sawdust. The optimal conditions were found to be $640^{\circ} \mathrm{C}, 8 \mathrm{~cm}$, and $180 \mathrm{~mL} / \mathrm{min}$, respectively. The bio-oil and bio-char yield at optimum conditions were determined to be $48.70 \%$ and $25.56 \%$, respectively [12]. Baruah et al. investigated the influence of different pyrolysis reaction conditions such as reaction temperature, heating rate, and size of the particle on different product yields from the pyrolysis of oil shale by using the CCD model in RSM. The optimal values of parameters such as heating rate, pyrolysis temperature, and particle size were found to be $10{ }^{\circ} \mathrm{C} / \mathrm{min}, 600{ }^{\circ} \mathrm{C}$, and $0.150 \mathrm{~mm}$, respectively. The bio-oil, gas, and aqueous phase yield in optimum conditions were predicted to be $14.56 \%, 9.12 \%$, and $2.97 \%$, respectively[13].

In the present work, thermal degradation of three different types of biomass, such as seed biomass, de-oiled cake/seed residue biomass, and microalgae biomass, was carried out to evaluate a condition for optimizing the yield of different pyrolysis products. The temperature and biomass type were chosen as independent variables. The process was optimized by using response surface methodology with the aim of maximizing different product yield.

\section{Materials and Methods}

\subsection{Materials.}

Three different types of biomasses, such as Kaner seed (Thevetia peruviana), flax seed residue (Linum Usitatissimum L.), and microalgae (Arthrospira platensis) were taken in this experiment for study. The first biomass dried Kaner seed is seed biomass and contain high lipid contents, while the second is a seed residue is a with major component fibers in addition to few protein and lipid whereas the third one is algal biomass with a high protein component. So these three biomass can be considered as a representative biomass sample available all around us. The dried Kaner seeds are crushed to about less than $1 \mathrm{~mm}$ size before using it for pyrolysis. Flaxseed residue and microalgae biomass was used as procured in the powered form of less than $1 \mathrm{~mm}$ size in pyrolysis experiments.

\subsection{Methods.}

\subsubsection{Pyrolysis experiments.}

The pyrolysis of three different biomasses was performed in a semi-batch reactor used in our previously reported work of capacity $300 \mathrm{ml}$, comprising of a stainless steel tube reactor, which is sealed at one end and an outlet tube at another end [14]. The reactor was heated 
externally by an electric furnace, and the temperature was controlled by an external PID controller with a $\mathrm{Cr}-\mathrm{Al}$ : $\mathrm{K}$ type thermocouple fixed inside the reactor to maintain the desired temperature with a heating rate of $20^{\circ} \mathrm{C}$ per minutes. The carrier gas nitrogen was used with a flow rate of $5 \mathrm{ml} / \mathrm{min}$ for all the experiments. $30 \mathrm{~g}$ of the biomass sample was placed into the stainless tube, and it was inserted inside the furnace after attaining the desired temperature ranging from $400^{\circ} \mathrm{C}$ to $600^{\circ} \mathrm{C}$. Vapors obtained during the process were condensed in a glass condenser by using tap water as cooling media at the outlet of the reactor, and the condensed liquid was collected in a container. The liquid fraction thus obtained was weighed, and the yield percentage was calculated. The residue left in the reactor after the pyrolysis process was measured as char. The yield of non-condensable gas, was calculated by material balance. The condensed pyrolysis liquid product consisting of oil and some aqueous phase could be separated by a separating funnel to obtain only bio-oil free from the aqueous phase. The percentage yield of condensable liquid fraction, oil, char, and non-condensable volatiles was calculated as per equation 1, 2, 3, and 4. The pyrolysis experiments were repeated three times to ensure the reproducibility of the results.

$$
\begin{aligned}
& \text { Condensable fraction }(\%)=\frac{W_{c}}{W} \times 100 \\
& \text { Oil fraction }(\%)=\frac{W_{0}}{W} \times 100 \\
& \text { Char fraction }(\%)=\frac{W_{c h}}{W} \times 100 \\
& \text { Non condensable fraction }(\%)=\frac{W_{n c}}{W} \times 100
\end{aligned}
$$

Where,

$W=$ Weight of feedstock

$W_{c}=$ Weight of a condensable fraction

$W_{0}=$ Weight of oil fraction

$W_{c h}=$ Weight of char fraction

$W_{n c}=$ Weight of non-condensable fraction

\subsubsection{Optimization experiments.}

Response surface methodology (RSM) is a combination of the statistical as well as mathematical tools that uses quantitative and appropriate experimental data to define regression model equations and operating conditions, and it also provides statistical models which support in illustrating the interactions between the parameters which have been optimized [15]. Moreover, RSM is one of the model techniques and optimization approaches that uses suitable experimental data to improve the process parameters [16]. The statistical software package Design-Expert, Stat-Ease, Inc., Minneapolis, USA, has been used for developing a polynomial regression equation of the responses to plot response surface and ANOVA to estimate the statistical parameters. A standard RSM design called User Defined Method was applied in this work to study the variation of product distribution and reaction time with temperature and type of biomass.

The User Defined Method was generally used for fitting a model of second-order. With the help of this method, modeling can be possible by performing fewer number of experiments. The detailed information is not required in the modeling procedure as the mathematical model is empirical. This experimental design consists of a $2^{n}$ factorial runs (coded to the usual \pm 1 notation) with $2 n$ axial runs with axial points $( \pm \alpha, 0,0, \ldots, 0),(0, \pm \alpha, 0, \ldots, 0), \ldots,(0,0, \ldots$ 
$., \pm \alpha)$ and $n_{\mathrm{c}}$ center runs with center points $(0,0,0, \ldots, 0)$ [17]. Each variable is examined at two levels. In the meantime, the number of runs for a complete replicate of the design increases as the number of factors $n$ increases. In this case, the interactions and effects of optimized factors may be estimated by fractional factorial designs running only a minimum number of experiments. Though in this study, out of two independent variables, one is categorical, and the other is numerical, so the user-defined model has been chosen. The analysis of variance (ANOVA) was used to evaluate whether the model (regression equation) is fitted with the experimental data. The responses and the corresponding parameters were modeled and optimized using analysis of variance (ANOVA).

The optimization process mainly consists of three steps, which involve the performing of the statistically designed experiments, estimation of the coefficients in a mathematical model, and checking the adequacy level of the model and predicting the responses. The responses as a function of a set of independent variables are shown in equation (5).

$$
Y=f\left(X_{1}, X_{2}, X_{3}, \ldots \ldots \ldots, X_{n}\right)
$$

In equation (5), $\mathrm{Y}$ is the response of the system, and $X_{i}$ represents the variables of action referred to as factors. The objective of this study is to optimize the response variables $(Y)$. It is presumed that the independent variables are continuous and can be controlled by means of experiments with insignificant errors. A suitable approximation is required to generate for the functional relationship between the response variables and the independent variable [18].

The effects of the uncontrolled factors are minimized by randomizing the experimental sequence. The response has been used to develop an empirical model that correlates the response to temperature and type of biomass variable using a second-order polynomial equation as specified by equation (6)[19-21].

$$
Y=\beta_{0}{ }^{\prime}+\sum_{i=1}^{n} \beta_{i}{ }^{\prime} X_{i}+\sum_{i=1}^{n} \beta_{i i}^{\prime} X_{i}{ }^{2}+\sum_{i=1}^{n} \sum_{j>1}^{n} \beta_{i j}{ }_{i j} X_{i} X_{j}
$$

Where $Y$ is the predicted response, $\beta_{0}{ }^{\prime}$, the constant coefficient $\beta_{i}^{\prime}$, the linear coefficients, $\beta_{i i}^{\prime}$ , the quadratic coefficients $\beta_{i j}^{\prime}$, the interaction coefficients, and $X_{i}, X_{j}$ are the coded values of the responses. The number of experiments necessary for the user-defined model involves the standard $2^{n}$ factorials, $2 n$ points fixed axially at a distance ( $\operatorname{say} \alpha$ ), from the center to create the quadratic terms, and replicate tests at the center; where $n$ is the number of variables. The axial points are selected so that they allow ratability [22]. This makes sure that the variance of the model estimation is constant at all points midway between the design centers. Replicates of the test at the center provide an independent estimate of the experimental error. For three variables, the recommended number of tests at the center is six [23]. Hence, the total number of tests $(N)$ required for the above study is given by equation (7):

$$
N=2^{n}+2 n+n_{c}
$$

Where $\mathrm{n}$ represents the number of variable factors.

The variables are coded to lie at \pm 1 for the factorial points, 0 for the center points, and $\pm \alpha$ for the axial points. Table 1 shows the calculated values of codes as a function of the range of interest of each factor [24].

Table 1. Actual value and corresponding coded value of the variables.

\begin{tabular}{l|l} 
Code & Actual level of variable \\
\hline$-\alpha$ & $A_{\min }$ \\
\hline-1 & {$\left[\left(\mathrm{~A}_{\max }+\mathrm{A}_{\min }\right) / 2\right]-\left[\left(\mathrm{A}_{\max }-\mathrm{A}_{\min }\right) / 2 \beta\right]$}
\end{tabular}




\begin{tabular}{l|l} 
Code & Actual level of variable \\
\hline 0 & $\left(\mathrm{~A}_{\max }+\mathrm{A}_{\min }\right) / 2$ \\
\hline+1 & {$\left[\left(\mathrm{~A}_{\max }+\mathrm{A}_{\min }\right) / 2\right]+\left[\left(\mathrm{A}_{\max }-\mathrm{A}_{\min }\right) / 2 \beta\right]$} \\
\hline$+\alpha$ & $\mathrm{A}_{\max }$
\end{tabular}

\section{Results and Discussion}

\subsection{Regression model equation.}

A series of pyrolysis experiments were carried out for thermal degradation of three different types of biomass such as Kaner (Thevetia peruviana) seed, flax (Linum Usitatissimum L.) seed residue and blue-green (Arthrospira platensis) microalgae biomass to evaluate a condition for optimizing the yield of different pyrolysis products using Response Surface Methodology (RSM). The results thus obtained were fed into the software to get the design of the experiment for optimizing the reaction parameters as well as the product distributions. To estimate the liquid yield, oil yield, char yield, gas yield, and reaction time, an empirical correlation has been developed by using statistical software package Design Expert-10. From the experimental data analysis, it has been observed that the above five response variables might be influenced by two independent variables, such as temperature and types of biomass. On the basis of experimental data, correlations have been developed by employing Response Surface Methodology (RSM). Analysis of Variance (ANOVA) is used to estimate the statistical parameters. The complete range of experimental data and the level of independent variables are shown in table 2 .

Table 2. Complete range of experimental data and the level of independent variables.

\begin{tabular}{|c|c|c|c|c|c|c|}
\hline Variable & Symbol & \multicolumn{5}{|c|}{ Range and levels } \\
\hline Temperature $\left({ }^{\circ} \mathrm{C}\right)$ [Numeric factor] & $\mathrm{A}$ & $400(-\alpha)$ & $450(-1)$ & $500(0)$ & $550(+1)$ & $600(+\alpha)$ \\
\hline Types of Biomass (categorical factor) & B & \multicolumn{2}{|c|}{ Kaner seed } & \multicolumn{2}{|c|}{ Flaxseed residue } & Microalga \\
\hline
\end{tabular}

According to the sequential model sum of squares, the models have been selected on the basis of highest order polynomials where the additional terms are significant, and the models are not aliased. Experiments have been planned to obtain a regression model consisting of $2^{2}$ trials plus a star configuration $(\alpha= \pm 2)$ and their replicates at the center point. Table 3 represents the design matrix of experiments with the obtained results.

Table 3. Design of experiments.

\begin{tabular}{|c|c|c|c|c|c|c|c|}
\hline Run & Temp. & Biomass & $\begin{array}{l}\text { Liquid } \\
\text { Yield (Y) }\end{array}$ & $\begin{array}{l}\text { Oil Yield } \\
\left(\mathbf{Y}_{2}\right)\end{array}$ & $\begin{array}{l}\text { Char } \\
\text { Yield (Y) }\end{array}$ & $\begin{array}{l}\text { Gas Yield } \\
\left(\mathbf{Y}_{4}\right)\end{array}$ & $\begin{array}{l}\text { Reaction } \\
\text { Time (Y) }\end{array}$ \\
\hline 1 & 450 & Kaner Seed & 69.2 & 66.8 & 18.1 & 12.7 & 38 \\
\hline 2 & 450 & Microalgae & 48.41 & 30.44 & 29.8 & 21.79 & 50 \\
\hline 3 & 500 & Microalgae & 56.922 & 36.44 & 20.9 & 22.178 & 43 \\
\hline 4 & 400 & Microalgae & 44.84 & 28.68 & 35.6 & 19.56 & 76 \\
\hline 5 & 550 & Flax Seed Extract & 44.43 & 25.63 & 25.67 & 29.9 & 32 \\
\hline 6 & 500 & Kaner Seed & 75.6 & 73.2 & 12.2 & 12.2 & 32 \\
\hline 7 & 550 & Microalgae & 54.62 & 33.24 & 19.6 & 25.78 & 33 \\
\hline 8 & 600 & Kaner Seed & 81.2 & 79 & 9.3 & 9.5 & 20 \\
\hline 9 & 500 & Flax Seed Extract & 50.67 & 31.57 & 27 & 22.33 & 49 \\
\hline 10 & 400 & Flax Seed Extract & 37.67 & 16.47 & 41.33 & 21 & 61 \\
\hline 11 & 600 & Flax Seed Extract & 35.73 & 17.23 & 23.67 & 40.6 & 23 \\
\hline 12 & 400 & Kaner Seed & 66.5 & 63.8 & 19.2 & 14.2 & 47 \\
\hline 13 & 600 & Microalgae & 53.8 & 32.2 & 18.2 & 28 & 22 \\
\hline 14 & 450 & Flax Seed Extract & 45 & 24.4 & 33.333 & 21.67 & 55 \\
\hline 15 & 550 & Kaner Seed & 79.7 & 77.4 & 9.8 & 10.5 & 25 \\
\hline
\end{tabular}

The regression analysis has been performed to fit the responses. The model is expressed in equation (6), where the variables take their coded value representing the responses ( $\mathrm{Y}_{1}$ to 
$\mathrm{Y}_{5}$ ) as a function of temperature (A) and type of biomass (B). The empirical model in terms of coded factor and actual for liquid yield, oil yield, char yield, gas yield, and reaction times of different biomasses are given in the equations (8-12) and equations (13-27), respectively.

In terms of coded factor, the empirical models for different responses are:

$\mathrm{Y}_{1}=59.5368+5.966666667 \mathrm{~A}+15.57462857 \mathrm{~B}[1]-10.55537143 \mathrm{~B}[2]+4.008 \mathrm{AB}[1]-$ $4.862 \mathrm{AB}[2]-6.501333333 \mathrm{~A}^{2}+5.15847619 \mathrm{~A}^{2} \mathrm{~B}[1]-6.06152381 \mathrm{~A}^{2} \mathrm{~B}[2]-2.346666667$ $\mathrm{A}^{3}$

$\mathrm{Y}_{2}=45.55571+5.42 \mathrm{~A}+27.19857 \mathrm{~B}[1]-15.9571 \mathrm{~B}[2]+4.627333 \mathrm{AB}[1]-3.02267 \mathrm{AB}[2]$

$-6.24476 \mathrm{~A}^{2}+4.81619 \mathrm{~A}^{2} \mathrm{~B}[1]-6.83238 \mathrm{~A}^{2} \mathrm{~B}[2]-2.17333 \mathrm{~A}^{3}$

$\mathrm{Y}_{3}=21.09939048-7.738866667 \mathrm{~A}-9.193533333 \mathrm{~B}[1]+7.287066667 \mathrm{~B}[2]+2.118866667$

$\mathrm{AB}[1]-0.857733333 \mathrm{AB}[1]+3.628285714 \mathrm{~A}^{2}$

$\mathrm{Y}_{4}=19.36701+3.156667 \mathrm{~A}-7.51844 \mathrm{~B}[1]+3.880133 \mathrm{~B}[2]-6.1 \mathrm{AB}[1]+5.706 \mathrm{AB}[2]+$ $2.853714 \mathrm{~A}^{2}-2.91086 \mathrm{~A}^{2} \mathrm{~B}[1]+4.852 \mathrm{~A}^{2} \mathrm{~B}[2]+0.733333 \mathrm{~A}^{3}$

$\mathrm{Y}_{5}=40.4-19.4 \mathrm{~A}-8 \mathrm{~B}[1]+3.6 \mathrm{~B}[2]+6 \mathrm{AB}[1]-0.4 \mathrm{AB}[2]$

In terms of actual factor, the model equations are:

For Kaner Seed,

$$
\begin{aligned}
& Y_{1}=285-1.525967619 \mathrm{~A}+0.003385714 \mathrm{~A}^{2}-2.34667 \times 10^{-06} \mathrm{~A}^{3} \\
& \mathrm{Y}_{2}=258.47-1.38667 \mathrm{~A}+0.003117 \mathrm{~A}^{2}-2.2 \times 10^{-6} \mathrm{~A}^{3} \\
& \mathrm{Y}_{3}=130.713-0.419028571 \mathrm{~A}+0.000362829 \mathrm{~A}^{2} \\
& \mathrm{Y}_{4}=-66.53+0.526281 \mathrm{~A}-0.00111 \mathrm{~A}^{2}+7.33 \times 10^{-07} \mathrm{~A}^{3} \\
& \mathrm{Y}_{5}=99.4-0.134 \mathrm{~A}
\end{aligned}
$$

For Flax seed extract,

$\mathrm{Y}_{1}=22.72+0.492667619 \mathrm{~A}+0.002263714 \mathrm{~A}^{2}-2.34667 \times 10^{-06} \mathrm{~A}^{3}$

$\mathrm{Y}_{2}=-37.65-0.29831 \mathrm{~A}+0.001952 \mathrm{~A}^{2}-2.2 \times 10^{-6} \mathrm{~A}^{3}$

$\mathrm{Y}_{3}=162.0766-0.448794571 \mathrm{~A}+0.000362829 \mathrm{~A}^{2}$

$\mathrm{Y}_{4}=79.91-0.13194 \mathrm{~A}+0.00033 \mathrm{~A}^{2}+7.33 \times 10^{-07} \mathrm{~A}^{3}$

$\mathrm{Y}_{5}=143-0.198 \mathrm{~A}$

For Microalgae,

$\mathrm{Y}_{1}=173.7904-1.131964762 \mathrm{~A}+0.002960171 \mathrm{~A}^{2}-2.34667 \times 10^{-06} \mathrm{~A}^{3}$

$\mathrm{Y}_{2}=181.19-1.16899 \mathrm{~A}+0.002837 \mathrm{~A}^{2}-2.2 \times 10^{-6} \mathrm{~A}^{3}$

$\mathrm{Y}_{3}=158.713-0.452828571 \mathrm{~A}+0.000362829 \mathrm{~A}^{2}$

$\mathrm{Y}_{4}=-63.6004+0.49425 \mathrm{~A}-0.00101 \mathrm{~A}^{2}+7.33 \times 10^{-07} \mathrm{~A}^{3}$

$\mathrm{Y}_{5}=169.8-0.25 \mathrm{~A}$

\subsection{Statistical analysis.}

The effects of experimental factors on liquid, oil, char, and gas yield are visualized by equations (8), (9), (10) and (11) respectively. The influence of reaction time by the experimental parameters is shown by equation (12). It is also important to check the adequacy level of the fitted model aforegoing on to optimization so as to avoid misleading results. This can be done by viewing the residual plot, which is examined for approximating the model. The residual Vs. Run plots for all the responses such as the liquid yield, oil yield, char yield, gas yield, and reaction time are displayed in figure 1 (a) to 1(e), respectively. In the residual plots, the points are dispersed randomly around the horizontal line, which shows that the regression model is well fitted for the data, and the responses are influenced by the variables in a systematic manner. There is no such alarm because all the points are lying within the red limits. 


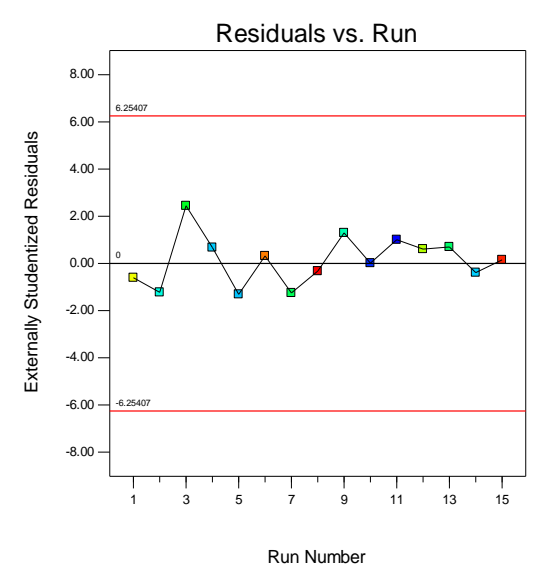

Figure 1 (a). Residual Vs. Run plot of liquid yield.

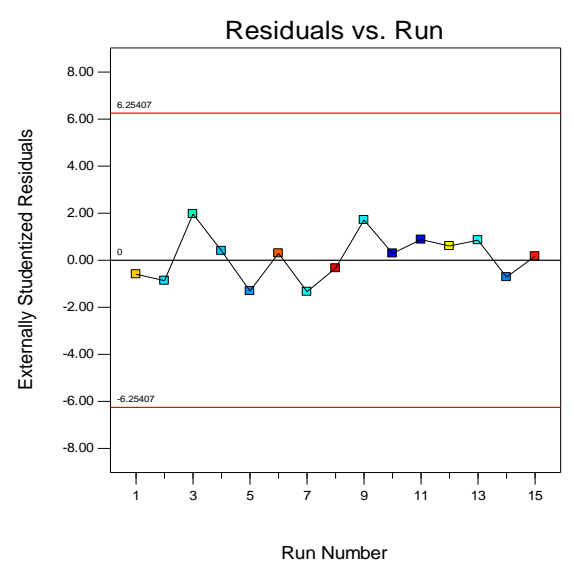

Figure 1 (b). Residual Vs. Run plot of oil yield.

The figures from 2 (a) to 2 (e) represent the predicted vs. actual value plots of liquid yield, oil yield, char yield, gas yield, and reaction time, respectively, which shows the comparison of the calculated values of responses with the experimental one. From the plot, one can interpret that all the points very less diverge from the straight line indicating that the data obtained from the experiments quite agree with the predicted values obtained from the development of the model.

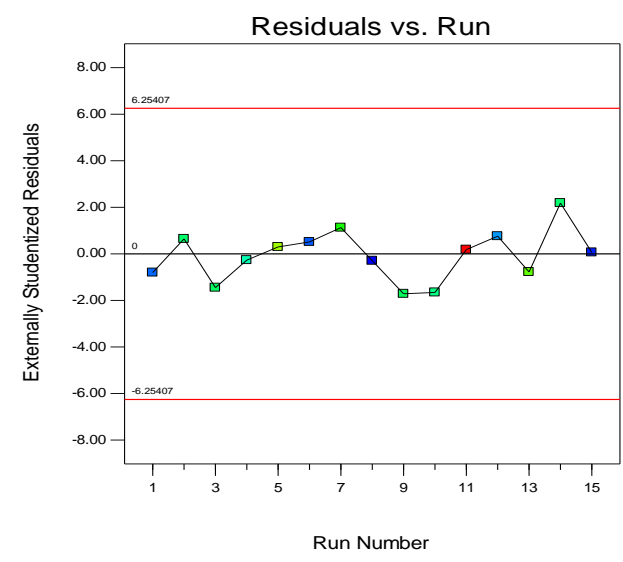

Figure 1 (c). Residual Vs. Run plot of char yield.

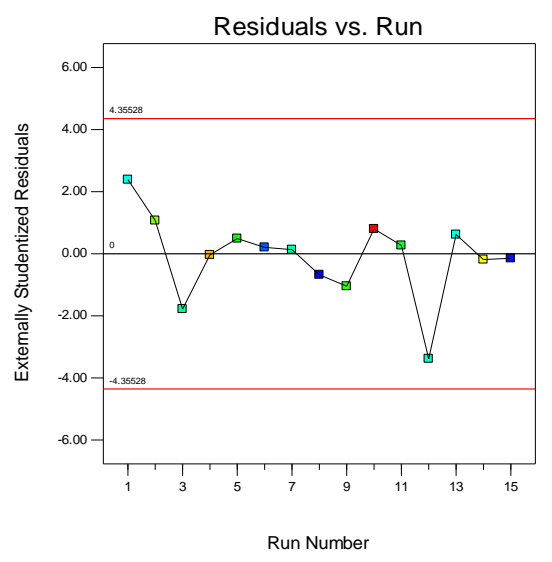

Figure 1 (d). Residual Vs. Run plot of gas yield.

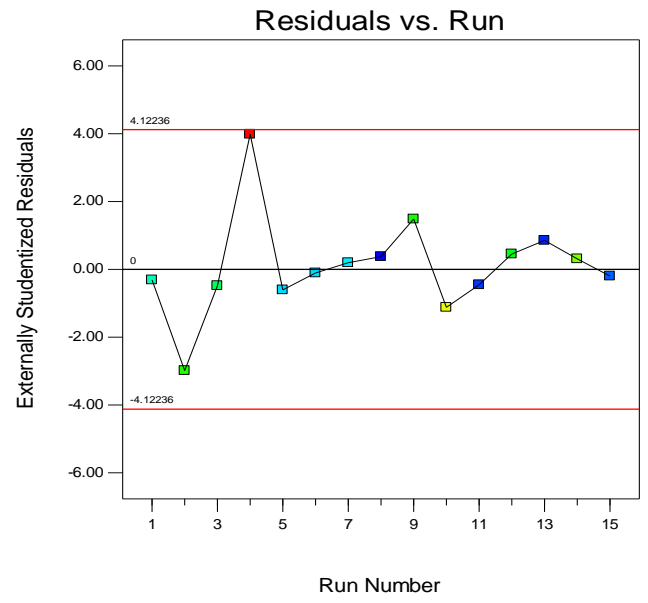

Figure 1 (e). Residual Vs. Run plot of reaction time. 

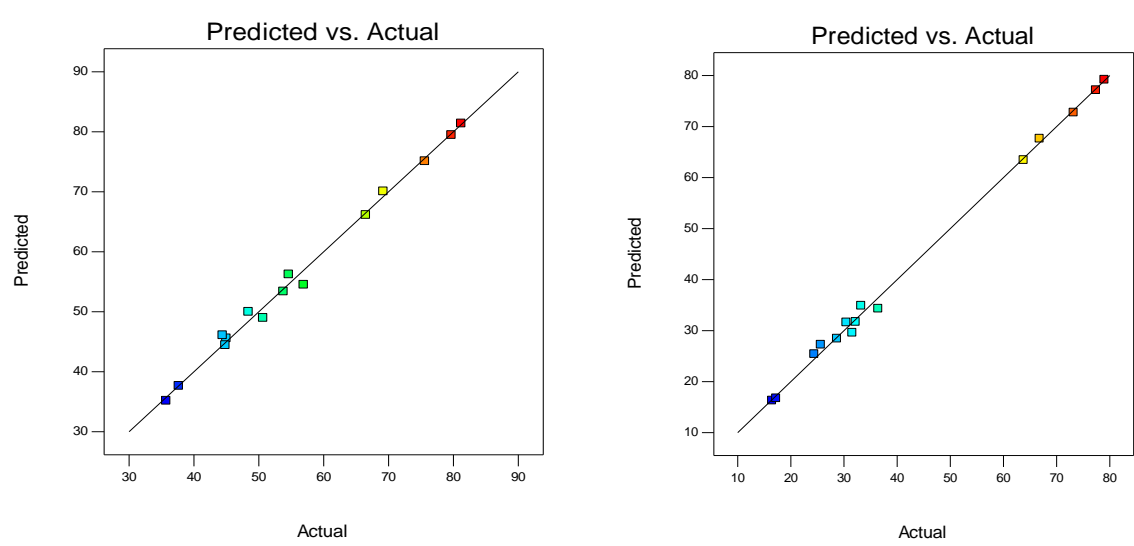

Figure 2 (a). Predicted Vs. actual plot of liquid yield. Figure 2 (b). Predicted Vs. actual plot of oil yield.
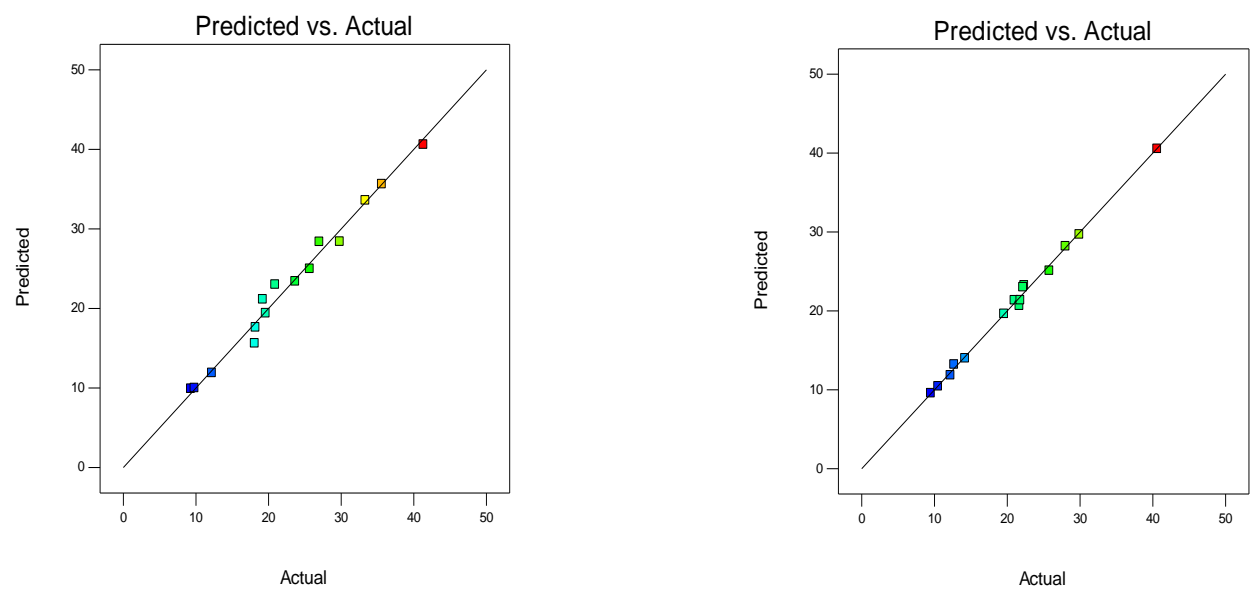

Figure 2 (c). Predicted Vs. actual plot of char yield. Figure 2 (d). Predicted Vs. actual plot of gas yield.

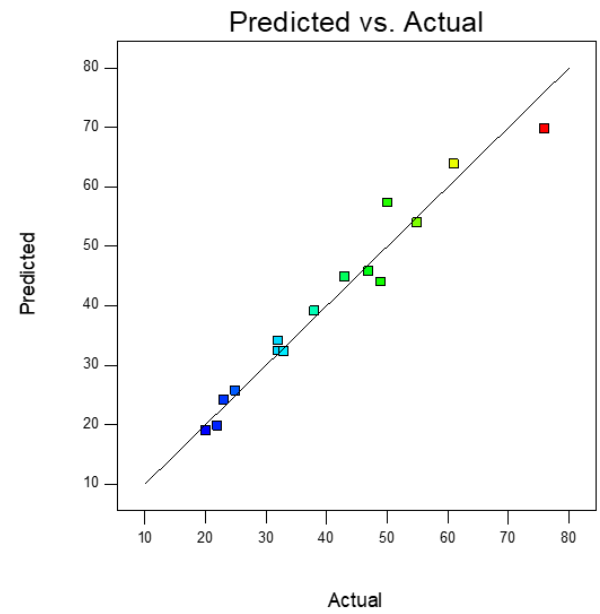

Figure 2 (e). Predicted Vs. actual plot of reaction time.

Analysis of variance (ANOVA) for the response surface quadratic model for liquid, oil, char, gas yield and reaction times are shown in table 4 (a-e) to evaluate the statistical significance of the coefficients of the model. From the ANOVA table, the F-values and Prob>F values are used to determine the significance of the terms in the regression model. The larger values of ' $F$ ' indicate the terms are significant [25]. As we can see from the table 4, The Fvalues for the liquid yield, Oil yield, Char yield, gas yield and reaction times are 90.76, 221.80, 
$76.67,139.92$ and 43.26 respectively, which indicate that the established quadratic models are significant.

Table 4. ANOVA for response surface quadratic models for liquid yield (a), oil yield (b), char yield (c), gas yield (d), and reaction time (e).

\begin{tabular}{l|l|l|l|l|l|l|l} 
Source & $\begin{array}{l}\text { Sum } \\
\text { Squares }\end{array}$ & $\begin{array}{l}\text { Degrees of } \\
\text { freedom (df) }\end{array}$ & Mean Square & F- Value & $\begin{array}{l}\text { p-value } \\
\text { Probability }>\text { F }\end{array}$ & Remarks \\
\hline \multicolumn{7}{|c|}{ (a) ANOVA for response surface quadratic model for liquid yield } \\
\hline Model & 3065.272735 & 9 & 340.5858595 & 90.76014143 & 0.0000529603 & Significant \\
\hline $\mathrm{A}-\mathrm{A}$ & 118.32588 & 1 & 118.32588 & 31.53176594 & 0.002478184 & Significant \\
\hline $\mathrm{B}-\mathrm{B}$ & 2675.050409 & 2 & 1337.525204 & 356.4269429 & 0.00000404888 & Significant \\
\hline $\mathrm{AB}$ & 101.08106 & 2 & 50.54053 & 13.46816235 & 0.009698681 & Significant \\
\hline $\mathrm{A}^{2}$ & 110.9517547 & 1 & 110.9517547 & 29.56669123 & 0.002854494 & Significant \\
\hline $\mathrm{A}^{2} \mathrm{~B}$ & 56.14651219 & 2 & 28.0732561 & 7.481029005 & 0.031398704 & Significant \\
\hline $\mathrm{A}^{3}$ & 3.71712 & 1 & 3.71712 & 0.990547104 & 0.365303942 & Not significant \\
\hline Residual & 18.76296434 & 5 & 3.752592869 & & & \\
\hline Cor Total & 3084.0357 & 14 & & & & \\
\hline \multicolumn{7}{|l|}{$(\mathrm{b})$ ANOVA for response surface quadratic model for oil yield } & \\
\hline Model & 7131.803059 & 9 & 792.4225621 & 221.8046428 & 0.00000577529 & Significant \\
\hline $\mathrm{A}-\mathrm{A}$ & 95.72960333 & 1 & 95.72960333 & 26.79538858 & 0.003535848 & Significant \\
\hline $\mathrm{B}-\mathrm{B}$ & 6783.009333 & 2 & 3391.504667 & 949.3059852 & 0.000000353573 & Significant \\
\hline $\mathrm{AB}$ & 82.80920667 & 2 & 41.40460333 & 11.58943939 & 0.013262205 & Significant \\
\hline $\mathrm{A}^{2}$ & 102.3672595 & 1 & 102.3672595 & 28.65331518 & 0.003057002 & Significant \\
\hline $\mathrm{A}^{2} \mathrm{~B}$ & 64.69937619 & 2 & 32.3496881 & 9.054904989 & 0.021773792 & Significant \\
\hline $\mathrm{A}^{3}$ & 3.18828 & 1 & 3.18828 & 0.892421973 & 0.388198535 & Not significant \\
\hline Residual & 17.86307429 & 5 & 3.572614857 & & & & \\
\hline Cor Total & 7149.666133 & 14 & & & & \\
\hline
\end{tabular}

(c) ANOVA for response surface quadratic model for char yield

\begin{tabular}{l|l|l|l|l|l|l}
\hline Model & 1207.056584 & 6 & 201.1760973 & 79.67820613 & 0.00000107189 & Significant \\
\hline $\mathrm{A}-\mathrm{A}$ & 449.1754296 & 1 & 449.1754296 & 177.9013161 & 0.000000954342 & Significant \\
\hline $\mathrm{B}-\mathrm{B}$ & 706.2850545 & 2 & 353.1425273 & 139.8663333 & 0.00000059759 & Significant \\
\hline $\mathrm{AB}$ & 17.03939927 & 2 & 8.519699633 & 3.374329221 & 0.086566503 & Not significant \\
\hline $\mathrm{A}^{2}$ & 34.55670021 & 1 & 34.55670021 & 13.68659558 & 0.006046608 & significant \\
\hline $\mathrm{A}^{2} \mathrm{~B}$ & 20.19885809 & 8 & 2.524857261 & & & \\
\hline $\mathrm{A}^{3}$ & 1227.255442 & 14 & & & & \\
\hline Residual & & & & & & \\
\hline Cor Total & & & & & \\
\hline
\end{tabular}

(d) ANOVA for response surface quadratic model for gas yield

\begin{tabular}{l|l|l|l|l|l|l}
\hline Model & 972.0945125 & 9 & 108.0105014 & 139.9205896 & 0.0000181395 & significant \\
\hline $\mathrm{A}-\mathrm{A}$ & 107.163 & 1 & 107.163 & 138.8227066 & 0.0000774827 & Significant \\
\hline $\mathrm{B}-\mathrm{B}$ & 637.0720085 & 2 & 318.5360043 & 412.6427055 & 0.00000281421 & Significant \\
\hline $\mathrm{AB}$ & 174.80918 & 2 & 87.40459 & 113.2269697 & 0.0000685904 & Significant \\
\hline $\mathrm{A}^{2}$ & 21.37717371 & 1 & 21.37717371 & 27.69274016 & 0.003292374 & Significant \\
\hline $\mathrm{A}^{2} \mathrm{~B}$ & 31.31015029 & 2 & 15.65507514 & 20.28013309 & 0.003989876 & Significant \\
\hline $\mathrm{A}^{3}$ & 0.363 & 1 & 0.363 & 0.470242924 & 0.523370509 & Not significant \\
\hline Residual & 3.8597072 & 5 & 0.77194144 & & & \\
\hline Cor Total & 975.9542197 & 14 & & & &
\end{tabular}

\begin{tabular}{l|l|l|l|l|l|l}
\multicolumn{7}{c}{ (e) ANOVA for response surface quadratic model for reaction time } \\
\hline Model & 3473.1 & 5 & 694.62 & 43.26352941 & 0.00000500856 & significant \\
\hline A-A & 2822.7 & 1 & 2822.7 & 175.8083045 & 0.00000032769 & Significant \\
\hline B-B & 481.6 & 2 & 240.8 & 14.99792388 & 0.00136304 & Significant \\
\hline AB & 168.8 & 2 & 84.4 & 5.256747405 & 0.030731484 & Significant \\
\hline Residual & 144.5 & 9 & 16.05555556 & & & \\
\hline Cor Total & 3617.6 & 14 & & & &
\end{tabular}

The developed model and the model terms are said to be significant if the P-values are less than 0.05[26-28] and non-significant if the P-value is greater than 0.01. It can be concluded that the terms $\mathrm{A}, \mathrm{B}, \mathrm{AB}, \mathrm{A}^{2}, \mathrm{~A}^{2} \mathrm{~B}$ for the responses liquid yield, oil yield, and gas yield are significant. The cubic term $A^{3}$ is a non-significant term in all the cases. Similarly, for the char yield, $\mathrm{A}, \mathrm{B}$, and $\mathrm{A}^{2}$ are the significant terms, and only the terms $\mathrm{A}, \mathrm{B}$, and $\mathrm{AB}$ are significant for the reaction time. The significant effects of the terms on the responses follow the order $\mathrm{B}>\mathrm{A}$ for the liquid, oil, and gas yield, But the order is the reverse (i.e., A>B) in case of char yield 
and the reaction time. The interaction between the type of biomass and the reaction temperature $\left(\mathrm{AB}, \mathrm{A}^{2} \mathrm{~B}\right)$ has a small effect on the responses, and so they are considered as negligible terms. From the F- values it can be interpreted that the term $\mathrm{B}$ has a larger significant effect on the liquid, bio-oil and gas yield because of the F-values 356.426, 949.305 and 412.642 respectively and while the char yield and reaction time is affected largely by the term A with F- values 177.901 and 175.808 respectively. The goodness of the fit of the developed model was summarized in table 5, which can be evaluated from the $\mathrm{R}^{2}$ (correlation coefficients) values, Adjusted and predicted $\mathrm{R}^{2}$ values, percentage of the coefficient of variance (\% CV) and adequate precision. The $\% \mathrm{CV}$ value is used to determine the replicability of the model by measuring the standard deviance by dint of a percentage of the mean. The signal to noise ratio can be calculated by using adequate precision values. The model will be considered as a good model if the signal to noise ratio is greater than 4[29]. The high values of adequate precision of the responses ( such as liquid yield $=29.22$, oil yield $=40.578$, Char yield $=28.280$, Gas yield $=43.168$ and reaction time 20.046) indicating the model is favorable. The low values of $\% \mathrm{CV}(<10)$ of all the responses in this design makes the results more reproducible. The $\mathrm{R}^{2}$ value tells about how the data in a scattered plot lie closely along a straight line. If $\mathrm{R}^{2}=1$, then the model is said to be more fit, and the error is nil, while $\mathrm{R}^{2}=0$ implies that the correlation is not linear. In this study, the $\mathrm{R}^{2}$ values of all the responses are greater than 0.950 , signifying a better correlation between the observed and predicted data [30]. However, the higher value of $\mathrm{R}^{2}$ is not sufficient to explain the favorability of a regression model. The higher values of the predicted and adjusted $\mathrm{R}^{2}$ support the more suitability of the model. In this work, the adjusted $R^{2}$ and predicted $R^{2}$ values are very close to the values of the correlation coefficient $\left(R^{2}\right)$, inferring the regression model is more promising.

\subsection{Optimization by RSM.}

One of the main objectives of this study is to find the optimum process parameters to maximize oil and liquid yield and to minimize char, gas yield and the reaction time from the mathematical model equation developed earlier in this study. The quadratic model equations (8-12) have been optimized by quadratic programming to maximize the responses within the experimental range studied. The interaction between the independent variables such as reaction temperature, type of biomasses, and the response variables are shown in figure 3 (a-e).

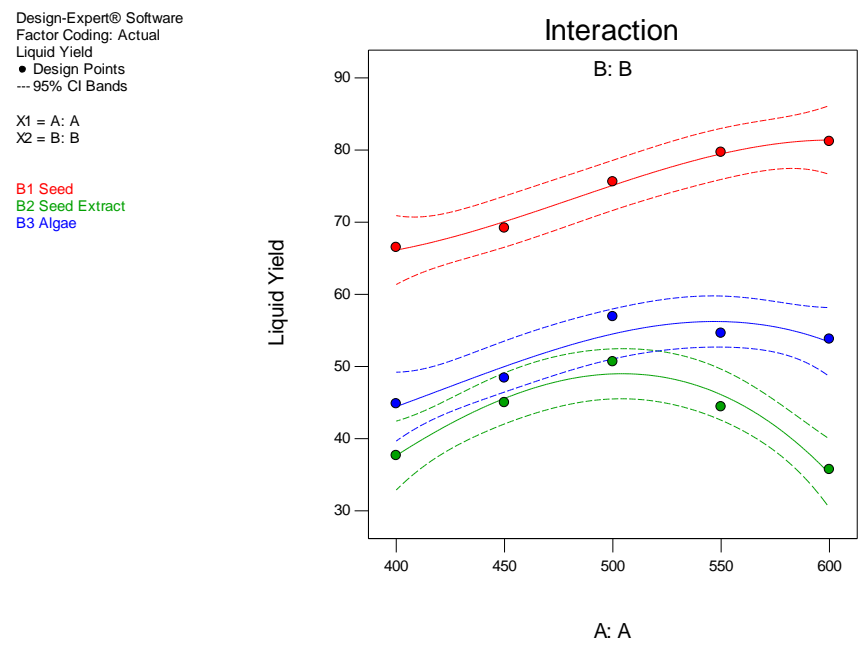

Figure 3 (a). Optimization of liquid yield. 

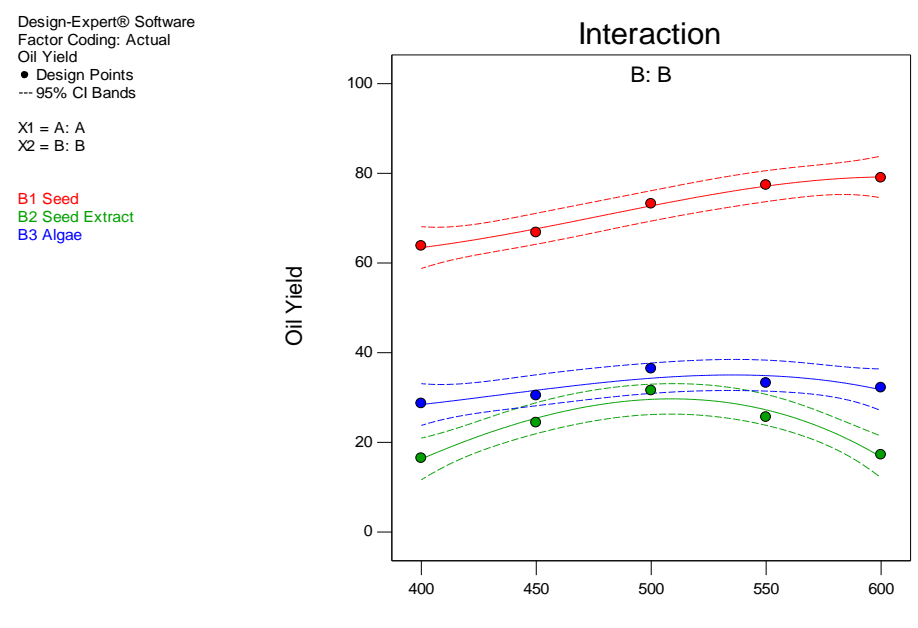

A: A

Figure 3 (b). Optimization of oil yield.
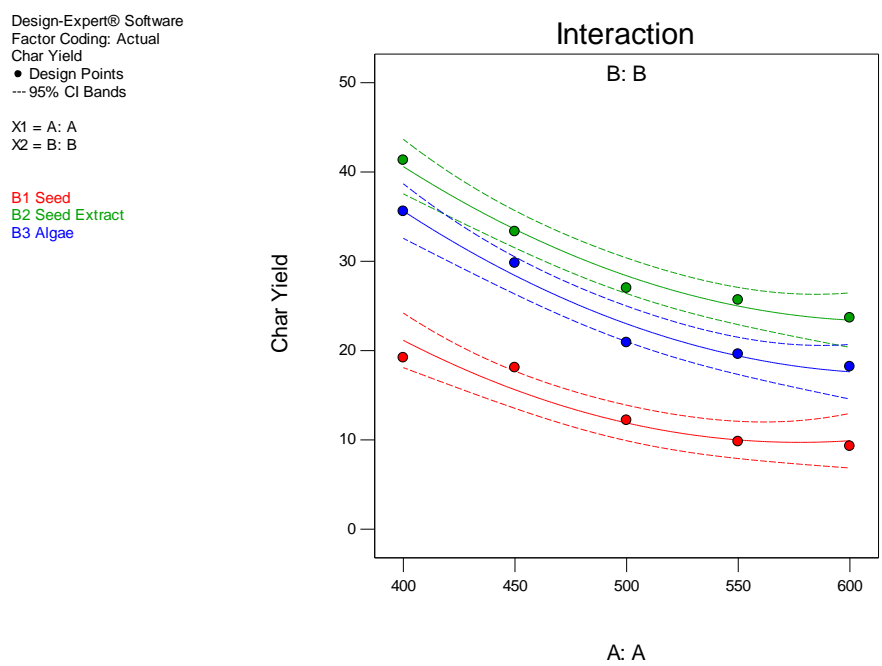

Figure 3 (c). Optimization of char yield.
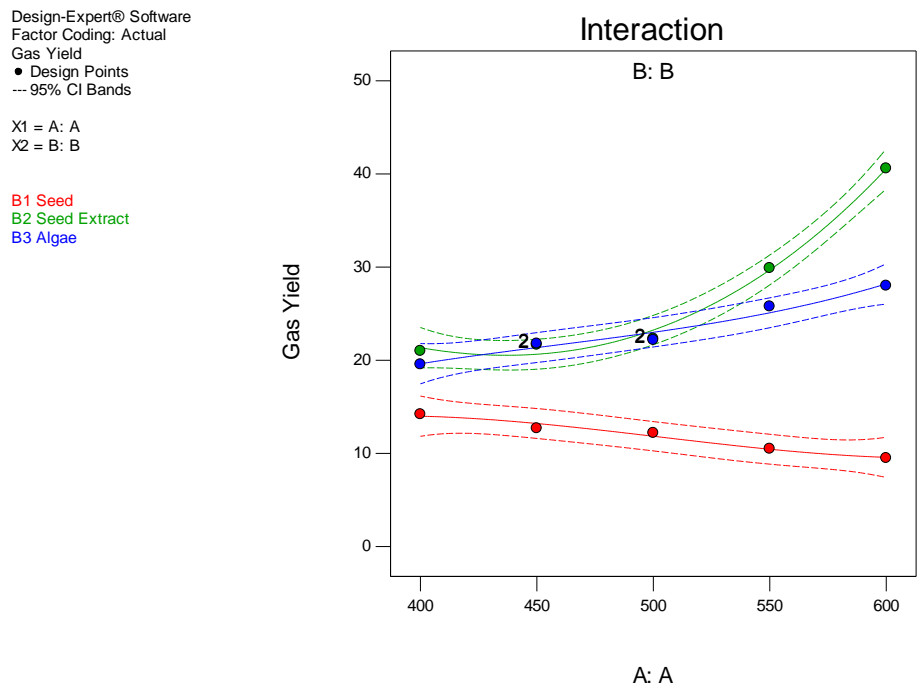

Figure 3 (d). Optimization of gas yield. 


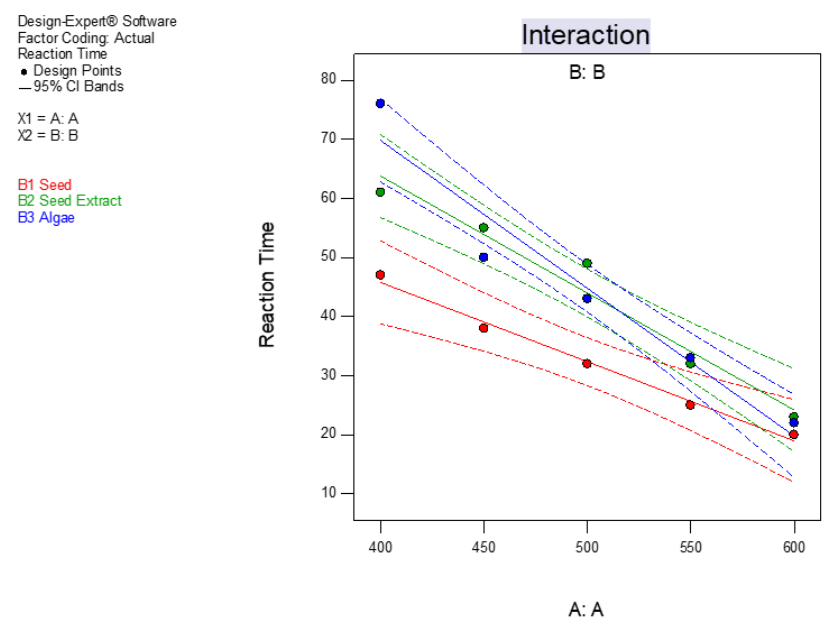

Figure 3 (e). Optimization of reaction time.

Table 5. Model summary statistics showing the goodness of fit of the developed model.

\begin{tabular}{l|l|l|l|l|l} 
Statistical Parameters & Liquid Yield & Oil yield & Char Yield & Gas Yield & Reaction Time \\
\hline Standard Deviation & 1.937 & 1.890 & 1.589 & 0.879 & 4.007 \\
\hline Mean & 56.286 & 42.433 & 22.914 & 20.794 & 40.4 \\
\hline \% of Coefficient of variation & 3.442 & 4.454 & 6.935 & 4.225 & 9.918 \\
\hline R-squared value & 0.994 & 0.998 & 0.984 & 0.996 & 0.960 \\
\hline Adj. R-squared value & 0.983 & 0.993 & 0.971 & 0.989 & 0.938 \\
\hline Pred. R-squared value & 0.938 & 0.976 & 0.929 & 0.950 & 0.858 \\
\hline Adequate precision & 29.222 & 40.758 & 28.280 & 43.168 & 20.046
\end{tabular}

From the above figures, it has been observed that for seed biomass at a temperature of $584^{\circ} \mathrm{C}$, the maximum value of liquid yield and oil yield is found to be $81.34 \%$ and $79.12 \% \mathrm{w} / \mathrm{w}$ respectively. At the same optimized condition, the minimum values of char yield, gas yield, and reaction time are found to be $9.82 \% \mathrm{w} / \mathrm{w}, 9.64 \% \mathrm{w} / \mathrm{w}, 19.89$ minutes, respectively. The optimum temperature for the other two biomasses, such as the seed extract and the microalgae, was found to be $500^{\circ} \mathrm{C}$. The liquid fraction, bio-oil, bio-char, gas yield and reaction time for the flaxseed extract and the microalgae in the optimal conditions are determined to be $50 \%$, $31.5 \%, 26.5 \%, 22 \%, 49 \%$ and $55.23 \%, 36.14 \%, 20.5 \%, 22 \%$, and 43 min respectively.

\section{Conclusions}

In this study, RSM and QP have been used to model and optimize the influence of two process parameters on oil yield, liquid yield, char yield, gas yield, and reaction time. These two process parameters are temperature and type of biomass. Mathematical model equations are derived for oil yield, liquid yield, char yield, gas yield, and reaction time by using sets of experimental data and ANOVA. Predicted values obtained using the model equations are in very good agreement with the experimental values. They are taking advantage of the QP, using seed biomass at a temperature of $584^{\circ} \mathrm{C}$ gives the maximum values of oil yield and liquid yield of 70.12 and $81.34 \%$. Similarly, at the same operating conditions, the minimum values of char yield, gas yield, and reaction time for the seed biomass are found to be 9.8, 9.64, and 19.89 minutes respectively. The results obtained in this study may be used for the design of a pyrolysis reactor for obtaining bio-oil from different biomass feedstocks in the experimental range of investigation. 


\section{Funding}

This research received no external funding.

\section{Acknowledgments}

This research has no acknowledgment.

\section{Conflicts of Interest}

The authors declare no conflict of interest.

\section{References}

1. Bridgwater, A.V. Review of fast pyrolysis of biomass and product upgrading. Biomass and bio energy 2012 , 38, 68-94, https://doi.org/10.1016/j.biombioe.2011.01.048.

2. Li, L.; Zhang, H.; Zhuang, X. Pyrolysis of Waste Paper: Characterization and Composition of Pyrolysis Oil. Energy Sources 2005, 27, 867-873, https://doi.org/10.1080/00908310490450872.

3. Wang, R.; Hou, Y.; Xu, Z. In-situ reaction for recycling indium from waste liquid crystal display panels by vaccum reduction with pyrolytic carbon as reductant. Waste Management 2019, 85, 538-547, https://doi.org/10.1016/j.wasman.2019.01.010.

4. Srivatsa, S.C.; Li, F.; Bhattacharya, S. Optimization of reaction parameters for bio-oil production by catalytic pyrolysis of microalga Tetraselmis suecica: Influence of Ni-loading on the bio-oil composition. Renewable Energy 2019, 142, 426-436.https://doi.org/10.1016/j.renene.2019.04.130.

5. Sakthivel, R.; Ramesh, K.; Marshal, S.J.J.; Sadasivuni, K.K. Prediction of performance and emission characteristics of diesel engine fuelled with waste biomass pyrolysis oil using response surface methodology. Renewable Energy 2019, 136, 91-103, https://doi.org/10.1016/j.renene.2018.12.109.

6. Saada, S.; Raei, E.; Talebbeydokhti, N. Enhanced removal of phosphate from aqueous solutions using a modified sludge derived biochar: Comparative study of various modifying cations and RSM based optimization of pyrolysis parameters. Journal of Environmental Management 2018, 225, 7583,https://doi.org/10.1016/j.jenvman.2018.07.037.

7. Roy, S.; Sengupta, S.; Manna, S.; Das, P. Chemically reduced tea waste biochar and its application in treatment of fluoride containing wastewater: Batch and optimization using response surface methodology. Process Safety and Environmental Protection 2018, 116, 553-563, https://doi.org/10.1016/j.psep.2018.03.009.

8. Pereira, I.C.; Carvalho, K.Q.; Passig, F.H.; Ferreira, R.C.; Rizzo-Domingues, R.C.P.; Hoppen, M.I.; Macioski, G.; Nagalli, A.; Perretto, F. Thermal and Thermal-acid treated sewage sludge for the removal of dye reactive Red 120: characteristics, kinetics, isotherms, thermodynamics and Response Surface Methodology design. Journal of Environmental Chemical Engineering 2018, 6, 72337246,https://doi.org/10.1016/j.jece.2018.10.060

9. Li, X.; Lei, T.; Wang, Z.; Li, X.; Wen, M.; Yang, M.; Chen, G.; He, X.; Xu, H.; Guan, Q.; Li, Z. Catalytic pyrolysis of corn straw with magnetic solid acid catalyst to prepare levulinic acid by response surface methodology. Industrial Crops and Products 2018, 116, 73-80, https://doi.org/10.1016/j.indcrop.2018.02.049.

10. Kim, P.; Haber, H.L.; Lloyd, J.; Kim, J.-W.; Abdoulmoumine, N.; Labbé, N. Optimization of thermal desorption conditions for recovering wood preservative from used railroad ties through response surface methodology. Journal of Cleaner Production 2018, 201, 802-811, https://doi.org/10.1016/j.jclepro.2018.08.097.

11. Intani, K.; Latif, S.; Cao, Z.; Müller, J. Characterisation of biochar from maize residues produced in a selfpurging pyrolysis reactor. Bioresource Technology 2018, 265, 224-235, https://doi.org/10.1016/j.biortech.2018.05.103.

12. Gupta, G.K.; Mondal, M.K. Bio-energy generation from sagwan sawdust via pyrolysis: Product distributions, characterizations and optimization using response surface methodology. Energy 2019, 170, 423-437. https://doi.org/10.1016/j.energy.2018.12.166.

13. Baruah, B.; Tiwari, P.; Thakur, P.; Kataki, R. TGA-FTIR analysis of upper assam oil shale, optimization of lab-scale pyrolysis process parameters using RSM. Journal of Analytical and Applied Pyrolysis 2018, 135, 397-405,https://doi.org/10.1016/j.jaap.2018.08.005

14. Gouda, N.; Panda, A.K.; Singh, R.K.; Ratha, S.K. Pyrolytic conversion of protein rich microalgae Arthrospira platensis to bio-oil.Res. J. Chem. Environ. 2018, 22, 54-65. 
15. Alam, M.Z.; Muyibi,S.A.; Toramae, J. Statistical optimization of adsorption processes for removal of 2,4dichlorophenol by activated carbon derived from oil palm empty fruit bunches.Journal of Environmental Sciences 2007, 19, 674-677,https://doi.org/10.1016/S1001-0742(07)60113-2.

16. de Oliveira, L.G.; de Paiva, A.P.; Balestrassi, P.P.; Ferreira J.R.; da Costa, S.C.; da Silva Campos, P.H. Response surface methodology for advanced manufacturing technology optimization: theoretical fundamentals, practical guidelines, and survey literature review.Int J Adv Manuf. Technol. 2019, 104, 17851837,https://doi.org/10.1007/s00170-019-03809-9.

17. Myers, R.H. Response Surface Methodology. Allyn and Bacon, New York, 1971.

18. Gunaraj, V.; Murugan, N.Application of response surface methodologies for predicting weld base quality in submerged arc welding of pipes.J. Mater. Process. Technol. 1999, 88, 266-275, https://doi.org/10.1016/S0924-0136(98)00405-1.

19. Saikia, R.; Baruah, B.; Kalita, D.; Pant, K.K.; Gogoi, N.; Kataki, R. Pyrolysis and Kinetic Analyses of a Perennial Grass (Saccharum ravannae L.) from North-East India: Optimization through Response Surface Methodology and Product Characterization.Bioresource Technology 2018, 253, 304314,https://doi.org/10.1016/j.biortech.2018.01.054

20. Kadlimatti, H.M.; Raj Mohan, B.; Saidutta, M.B. Bio-oil from microwave assisted pyrolysis of food wasteoptimization using response surface methodology. Biomass and Bioenergy 2019, 123, 25-33, https://doi.org/10.1016/j.biombioe.2019.01.014

21. Yıldız, Z.; Kaya, N.; Topcu, Y.; Uzun, H. Pyrolysis and Optimization of Chicken Manure Wastes in Fluidized Bed Reactor: $\mathrm{CO}_{2}$ Capture in Activated Bio-chars. Process Safety and Environmental Protection 2019, 130, 297-305,https://doi.org/10.1016/j.psep.2019.08.011

22. Box, G.E.P.; Hunter, J.S. Multi-factor experimental design for exploring response surfaces.Ann Math Stat.1957, 28, 195-241. https://doi.org/10.1214/aoms/1177707047.

23. Box, G.E.P.; Hunter, J.S. The 2k-p fractional factorial designs, parts I. Technometrics. 2000, 42, 28-47, https://doi.org/10.1080/00401706.2000.10485977.

24. Napier-Munn, T.J. The Central Composite Rotatable Design JKMRC. The University of Queensland, Brisbane, Australia, 2000, 1-9.

25. Sulaiman, N.S.; Hashim, R.; Mohamad Amini, M.H.; Danish, M.; Sulaiman, O. Optimization of activated carbon preparation from cassava stem using response surface methodology on surface area and yield.Journal of Cleaner Production 2018, 198, 1422-1430, https://doi.org/10.1016/j.jclepro.2018.07.061.

26. Kumar, M.; Mishra, P.K.; Upadhyay, S.N. Pyrolysis of Saccharum munja: Optimization of process parameters using response surface methodology (RSM) and evaluation of kinetic parameters. Bioresource Technology Reports 2019, 8, https://doi.org/10.1016/j.biteb.2019.100332.

27. Qian, M.; Lei, H.; Villota, E.; Mateo, W.; Zhao, Y.; Huo, E.;Zhang, Q.; Lin, X.; Huang, Z. Optimization of delignification from Douglas fir sawdust by alkaline pretreatment with sodium hydroxide and its effect on structural and chemical properties of lignin and pyrolysis products. Bioresource Technology Reports 2019, 8, https://doi.org/10.1016/j.biteb.2019.100339.

28. Dela Cruz, M.I.S., Thongsai, N., de Luna, M.D.G., In, I., Paoprasert, P.Preparation of highly photoluminescent carbon dots from polyurethane: Optimization using response surface methodology and selective detection of silver (I) ion. Colloids and Surfaces A: Physicochemical and Engineering Aspects 2019, 568, 184-194, https://doi.org/10.1016/j.colsurfa.2019.02.022.

29. Samavati, V.; Adeli, M. Isolation and characterization of hydrophobic compounds from carbohydrate matrix of Pistacia atlantica. Carbohydr Polym. 2014, 101, 890-896,https://doi.org/10.1016/j.carbpol.2013.09.069.

30. Mohseni-Bandpei, A.; Majlesi, M.; Rafiee, M.; Nojavan, S.; Nowrouz, P.; Zolfagharpour, H. Polycyclic aromatic hydrocarbons (PAHs) formation during the fast pyrolysis of hazardous health-care waste. Chemosphere 2019, 227, 277-288, https://doi.org/10.1016/j.chemosphere.2019.04.028. 